\title{
Prevalence of Diarrhoeal Diseases Among Children under Five Years in East African Countries from 2012-2017
}

\author{
O.E. ELMI ${ }^{1 *}$ AND R. (II) P. DIOSO ${ }^{2}$
}

\begin{abstract}
This meta-analysis analyzed the prevalence of diarrheoal diseases among children less than five years in three selected East African countries from 2012-2017. Search engines used Google Scholar, Proquest, and PubMed. Primarily, 300 studies were selected; hence 297 were eliminated using inclusion and exclusion criteria. The PICO (population, intervention, comparison, and outcome) guide helped in the analysis of the three selected studies. The prevalence of diarrhoea among children less than five years in the three selected East African countries from 2012 to 2017, averaged to 27\% range from a minimum of $11 \%$ to a maximum of $54 \%$ of the 5478 total respondents (OR 2.07). The five-year prevalence escalated extensively at Kenya, Ethiopia, and Somalia. There is a $207 \%$ risk of further escalation.
\end{abstract}

Key words: Diarrhoea; East Africa; meta-analysis; nursing; public health

Diarrhoeal diseases are the most major health problems in the world which cause highest mortality and morbidity in children especially in children less than five years, and they can also affect children's growth and development (World Health Organization 2001). Diarrhoea becomes the primary burden of all water and sanitation related diseases.

Globally about 4 million cases of diarrhea are recorded annually, and this causes about 2.2 million deaths, mostly among children under the age five (United Nations Children's Fund/World Health Organization 2009).

About $50 \%$ of deaths are due to acute watery stool, $35 \%$ are due to persistent diarrhoea, and $15 \%$ are due to dysentery (United Nations Children's Fund/World Health Organization 1999). According to World Health Organization, in developing countries, diarrhoea is the major cause of child death when children are less than five years old (World Health Organization 2000). Diarrhoea mortality is mainly due to dehydration which is the first direct consequence (United Nations Children's Fund/World Health Organization 1999). Diarrhoea morbidity is one of the major health burdens among infants and young children in low-income countries (Cunliffe et al. 1999).

An incidence of 3.2 episodes of diarrhoea per child per year among children below five years old was estimated between 1990 and 2000 within 20 countries (World Health Organization 1996). The immediate impact of diarrhoeal infant diseases regarding morbidity, hospitalization and death has been proved in several studies (United Nations Children's Fund/World Health Organization 1999).

\footnotetext{
${ }^{1}$ East Africa University, Somalia

${ }^{2}$ Lincoln University College, Jalan SS 6/12, 47301 Petaling Jaya, Malaysia

* Corresponding author (e-mail: elmiomar11@gmail.com)
} 
In developing countries, diarrhoeal diseases represent one-third of the hospitalizations (World Health Organization 1996). Children who were not looked after by their mothers, and those were partially breastfed or weaned children are at risk for diarrhoeal morbidity (Jensen et al. 2002). The long-term consequence is under-nutrition when episodes are repeated and prolonged (Cairncross \& Feachem 1993). Poor socio-economic status, sanitation and living conditions, nutrition and hygiene behaviour are the health determinants for diarrhoea prevalence (Jensen et al. 2002).

In Africa and especially Sub-Saharan Africa, diarrhoeal diseases account for over $90 \%$ of deaths in children below five years old (World Health Organization 2007). This has been attributed to lack of safe drinking water, sanitation and hygiene as well as poor nutrition (World Health Organization 2005). Accordingly, improved water sources reduce diarrhoea morbidity by $21 \%$, improved sanitation by $37.5 \%$ and hand washing by as much as 35\% (Roberts et al. 2001; World Health Organization 2007).

\section{METHODS}

\section{Literature Searches}

Google Scholar, Proquest and PubMed were searched from similar research articles related to the prevalence of diarrhoeal diseases in East African countries. Search strategy started with using keywords entered on search engines on the internet as English text words.

\section{Study Selection}

The inclusion criteria were: a populationbased study with participants under five years children; random sampling of a defined population or studies involving entire; studies involving African participants living in East African countries. Data extracted from each paper included country where research was conducted.

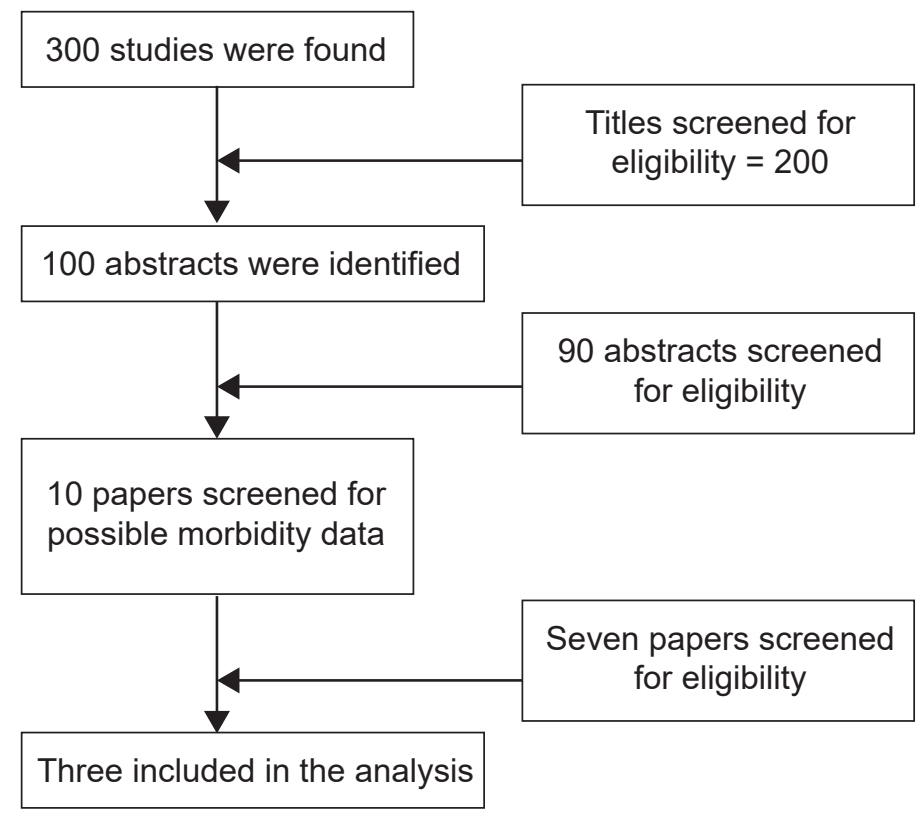

Figure 1. Data extraction. 


\section{Data Extraction}

Extracted data were collected using the PICO (population, intervention, comparison, outcome) guide. Of the 300 studies found on search engines, only three were selected (Figure 1). The study design method, sample size, and reported prevalence rate was analyzed by comparing factors related to occurrences of diarrhoea.

\section{RESULTS}

A total of three studies that fulfilled the inclusion criteria were used for the metaanalysis as shown in Table 1. All the studies adopted a cross-sectional design method. In the majority of the studies, diarrhoea was measured in a single visit of the children's caregivers by asking incidences of diarrhoea among their children in last two weeks. All the studies used children less than 5 years old. Prevalence of diarrhoea varied extensively between studies, ranging from a minimum of $11 \%$ to a maximum of $54 \%$.

Furthermore, this study summarized prevalence of diarrhoea in 3 East African countries for a five years period (2012 to 2017). The prevalence of diarrhoea from the three counties was $11 \%$ in Somalia, $16 \%$ in Kenya and $54 \%$ in Ethiopia. The total population was 1480 of the $5478(27 \%)$.
In Kenya, according to Kawakatsu et al. (2017), a total of 278 mothers were participated in the study. Of the 278 participants, 150 (54\%) children had acute diarrhoea. Only family income and current breast feeding status of the children were significantly associated with diarrhoea [AOR at 95\% CI, $0.59(0.21-1.65)$ ] and [AOR at $95 \% \mathrm{CI}, 0.36(0.16-0.80)$, respectively].

In Somalia according to Mohamed et al. (2016), a total of 245 under-five children were identified from Bosaso city, to be a total of $23(9.4 \%)$ children with diarrhoeal diseases who had a watery type of diarrhoea. The northeastern regions of Somalia on the southern coast of the Gulf of Aden have caregivers to report children in the month before the day of the interview, having only 26 (11\%) diarrhoeal cases. About 7.34\% reported 1 episode and only $2.85 \%$ reported 2 episodes and $0.4 \%$ reported 3 . Diarrhoea also occurred more often in children who were not exclusively breastfed (OR 3.9).

In Ethiopia, according to Mengistie et al. (2013), 4955 children under five and their family members living in Nyanza Province had diarrhoea. This Sample was used to determine the prevalence of childhood diarrhoea in Kenya at about $16 \%$ from the total respondents.

Table 1. The PICO Guide.

\begin{tabular}{|c|c|c|c|c|}
\hline Comparison & Intervention & \multicolumn{2}{|c|}{ Population } & Outcome \\
\hline Mohamed et al. (2016) & $\begin{array}{l}\text { Determined the } \\
\text { prevalence of diarrhoea }\end{array}$ & Somalia & 245 & $11 \%$ \\
\hline Mengistie et al. (2014) & $\begin{array}{l}\text { Determined the } \\
\text { prevalence of diarrhoea }\end{array}$ & Ethiopia & 4955 & $16 \%$ \\
\hline Kawakatsu et al. (2017) & $\begin{array}{l}\text { Assessed the prevalence } \\
\text { of diarrhoea }\end{array}$ & Kenya & 278 & $54 \%$ \\
\hline
\end{tabular}




\section{DISCUSSION}

Three important studies were extracted from search engines that address the risk factors associated with the prevalence of diarrhoea in the East Africa. The biases on selecting the studies are called selection biases. But considering the implications of diarrhoea and how harmful it will be is enough to ignore the biases implied.

In addition, occurrences of diarrhoea in this meta-analysis found 3 associated factors affecting it - (1) caregivers (2) age (3) surroundings.

Caregivers who are not mothers of the children are a factor associated with the occurrence of diarrhoeal diseases (OR 3.5) (Kawakatsu et al. 2017). The education level of the caregivers had an association with the occurrence of diarrhoea (Kawakatsu et al. 2017). Illiterate caregivers usually do not understand that milk can expire fast after diluted with water especially in warm climates (OR 1.6) (Mohamed, et al. 2016). Lastly, caregivers who are not giving enough time caring for children end up ignoring their dirty hands, that is usually sucked by children (OR 5.4) (Mengistie et al. 2013).

Children between 1 to 2 years old addressed the age as a factor associated with diarrhoeal diseases (OR 5.8) (Kawakatsu et al. 2017). Also, children who received other milk during the first six months of life (bottle feeding) also had occurrence of diarrhoea (OR 3.4) (Mohamed, et al. 2016). Similarly, Children who did not receive colostrums from breast milk had diarrhoea as well (OR 3.7873) (Mohamed et al. 2016).
Children living in unhygienic conditions addressed the surroundings as a factor associated with the occurrence of diarrhoeal diseases (OR 2.4) Mengistie et al. 2013. Those who were prematurely born without latrines had association diarrhoea (OR 1.04) (Mohamed et al. 2016). Similarly, those who have no separated drinking water storage had diarrhoea (OR 1.3) Mengistie et al. 2013.

\section{CONCLUSION}

The three studies from different east African countries revealed that children have the occurrence of diarrhoeal diseases less than five years of age that was $27 \%$ of the 5,478 total respondents (OR 2.07) from 2012 to 2017. Therefore, there is a $207 \%$ risk of further escalation of prevalence in East Africa.

Even though poor environmental conditions were believed to increase the risk of diarrhoeal disease, the majority of the environmental variables included in this study showed significant association with diarrhoea. Secondly, children who are 1 to 5 years old must be given breast milk (not exactly breastfed) to develop intestinal resistance to diarrhoea. Low family income per month may have no other choice but hire unintelligent caregivers who sometimes are uneducated and illiterate.

\section{REFERENCES}

World Health Organization 2001, 'WaterImmediate solutions for persistent problems', <URL: http://www.who.int/infpr-2001/en/200112.html>.

United Nations Children's Fund/World Health Organization 2009, 'Acute diarrhea is still a leading cause of child deaths in clinical management of acute diarrhea', Joinstatement, <www.unicef.org $>$. 
United Nations Children's Fund/World Health Organization 1999, Building partnerships for child health WHO/CHS/CAH/98, Department of Child Health and Adolescent Health and Development, Geneva.

World Health Organization 2000, Major causes of children mortality in developing countries Report, World Health Organization, Geneva.

Cunliffe, NA, Gondwe, JS \& Broadhead, RL 1999, 'Rotavirus G and P types in children with acute diarrhea in Blantyre, Malawil', Journal of Medical Virology, vol. 57, pp. 308-312.

World Health Organization 1996, World water day. Water immediate solutions for persistent problems, Water and Sanitation Fact Sheet, World Health Organization, Geneva.

Jensen, PK, Ensink JHJ \& Jayasinghe, G 2002, 'Domestic transmission routes of pathogens', Tropical Medicine and International Health, vol. 7, no. 7, pp. 604-609.

Cairncross, S \& Feachem, R 1993, Environmental health engineering in the tropics, an introductory text, 2nd edn, Wiley and Sons, New Jersey.

World Health Organization 2007, Socioeconomic status and it affects occurrence of diarrhea report, World Health Organization, Geneva.
World Health Organization 2005, Prevalence of diarrheal diseases Sub-Saharan Africa countries report, World Health Organization, Geneva.

Roberts, WL, Chartier, Y, Chartier, O, Malenga, G, Toole, M \& Rodka, H 2001, Keeping clean water clean in a Malawi refugee camp: a randomized intervention trial, World Health Organ, Geneva.

World Health Organization 2007 , Communicable diseases working group on emergencies communicable disease epidemiological profile or Horn of Africa, World Health Organization, Geneva.

Kawakatsu, Y, Tanaka, J, Ogawa, K, Ogendo, K \& Honda, S 2017, 'Community unit performance: factors associated with childhood diarrhea and appropriate treatment in Nyanza Province, Kenya', BMC Public Health, vol. 17, no. 202, pp.1-14.

Mohamed, et al. 2016, 'Factors related to the occurrence of diarrheal disease in under-five children of IDP's in Bosaso, Puntland-Somalia', World Journal of Medical Sciences, vol.1, no.1, pp. 54-59.

15. Mengistie, B, Berhane, Y \& Worku, A 2013, 'Prevalence of diarrhea and associated risk factors among children under-five years of age in Eastern Ethiopia - a cross sectional study', Open Journal of Preventive Medicine, vol. 3, no. 7, pp. 446-453. 